\title{
Assessing the Usability of WebGIS for Schools
}

\author{
Martin DÜREN and Thomas BARTOSCHEK \\ Institute f. Geoinformatics, Münster/Germany·m_duer02@uni-muenster.de
}

This contribution was double-blind reviewed as full paper.

\begin{abstract}
This work introduces concepts from usability engineering and user centered design into software development in the educational context. As still most digital geomedia on the educational market are based on classical GIS principles made for professionals there is a need for usable tools that fit the needs of students and teachers. A prototype WebGIS application for schools to present various geospatial datasets with an intuitive user interface will be presented. The used technologies and GUI elements are described. Usability tests with secondary school students are conducted and are used to assess the performance of the prototype web application in a realistic environment.
\end{abstract}

\section{Introduction}

Geographical Information Systems (GIS) have become part of our everyday life in the past decades. Today almost 50 years after the first GIS has been invented in Canada (TOMLINSON 1967), it has become subject of educational standards regarding the material taught in schools, too (i.e. GERMAN ASSOCIATION FOR GEOGRAPHY 2007). It has been 20 years that spatial information went beyond GIS when Goodchild proposed the science behind the systems (GOODCHILD 1992). As scientific field in general, their research questions and methods in particular find their way to society via different channels. One of these channels is the K-12 education system below the higher level (K-12).

When Goodchild coined a spatial literacy to appear in the curricula and in education on the same level as a mathematical and linguistic literacy (GOODCHILD 2006) he was speaking about a transdisciplinary competence to think spatially in all subjects: from STEM, to social sciences and arts. The NRC report "Learning to think spatially" was leading into this direction and presented solutions for GIS as a support system to think spatially (COMMITTEE ON SUPPORT FOR THINKING SPATIALLY 2006).

So GIS should be the system to let our children think spatially? Are we speaking about the systems we learn to use, by spending hours with click-through tutorials? At least that is, what most authorities understood to do. The terms around GIS were integrated into curricula worldwide, mostly in geography classes. Sometimes referred to as "WebGIS", sometimes as "Geoviewer" or similar terms. Meanwhile GIS is being used in school on several levels in a lot parts of the world (MILSON et al. 2011). But still this tool is not a support system as i.e. the calculator is for mathematics. GIS has big difficulties to be accepted by the majority of teachers as part of their toolkit for good and efficient teaching. 
This is mostly due to the complexity of the software and its interfaces (HöHNLE et al. 2011). The gap between the GI related teacher education and the need for implementation of those concepts in school remains large and the existing scientific approaches of (geography) didactics lack innovative methods and collaborations. It is not clear if teachers or their students can reach the point of understanding the importance of spatial information with the existing approaches. A lot of research has been done on taking available GI applications, i.e. GIS, Virtual Globes or WebGIS, and analyzing them for their purpose in education and their possibilities in fostering competencies. The problem is that most of the presented products were not developed for the use in school with the specifications needed for an educative use by children or youths. To sustainably integrate spatial information via geotechnologies into education for making clear its role in society and to reach spatial literacy we have to rethink the ongoing approaches.

The development of spatial learning apps as focused applications is a very young field of research. Usability of software and interaction (i.e. gestural input) but also of hardwareplatforms (i.e. tablets) and data plays an important role here, as well as concepts from digital game based learning and methods of measuring the impact on learning (i.e. with preand post-tests on spatial skills). Spatial literacy can be reached focusing on spatial learning in the (outdoor) environment with these support systems. Results of this research could lead into new kinds of (Geographic) Information Systems or simple map-apps, fit-for-education of people of all ages, usable, understandable and interoperable. This makes the research field of Human-Computer Interaction (HCI) a key aspect in designing GIS applications. HCI has always been an important aspect of GIScience as pointed to by GoODCHILD (1992), and it only gained importance with the growth and broad availability of the Internet. Designing a GIS application now requires a deeper understanding of spatial cognition, spatial ontologies, geographic visualization (HAKLAY \& ZAFIRI 2008) and of the web.

In this paper the focus lies on a mapping application specially designed for educational purposes. The age of the users ranges from 12 to 16 years, these are the students in the classes 7 to 9 in the German school system. The targeted audience consists mainly of students, who are casual users. This type of user only uses a piece of software from time to time, thus the applications needs to provide a steep learning curve and the users need to be able to remember how the system works very easily (NIELSEN 1993). Off-the-shelf GIS software as used by specialists require a deeper understanding of database systems, geography and cartography, which makes these systems hard to use and understand for non-specialists (TRAYNOR \& WILLIAMS 1995). The underlying system architecture and the actual processes required for a GIS to work must be hidden from the users in order to simplify interaction with the software. Aspects like these have to be considered when designing a web application for students. In order to further assess the requirements needed for a WebGIS to work in an educational environment with children and teenagers this paper deploys a prototypical WebGIS based on ArcGIS Server technology from ESRI. The web application is then put to test in a usability test with secondary school students.

\section{Existing WebGIS for Schools}

In Germany the term WebGIS used in an educational context describes web applications providing features like map navigation, map design and simple SQL queries in thematic maps based on curricular content. These WebGIS applications merely need to fulfill the 
demands set by the educational guidelines. The applications in fact are not strictly WebGIS; nor can they replace a fully-fledged GIS. In this research we refer to this kind of application, when speaking of WebGIS.

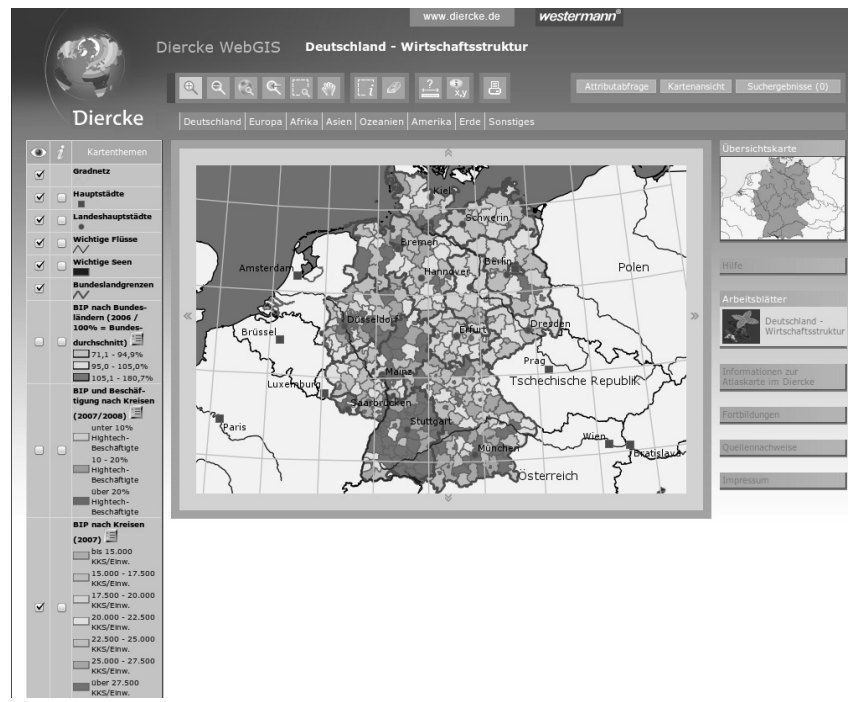

Fig. 1:

The Diercke WebGIS

Currently there are five major WebGIS applications that are being used for teaching in German schools. Two of them come from book publishers, which are very popular in German schools. The Diercke geographic atlas for schools was published first in 1883 and since then has been prominent in geography classes around Germany. On their website they provide a WebGIS application specially designed for teaching ${ }^{1}$. The website provides worksheets for teachers and assistance for teaching geography and GIS. The GIS provides sensible data and has other valuable features such as a good function to print the created maps. The main view is complex and bulky menus surround a small map. Some of the visible menus do not apply to any mapping function and can be distracting for users. NIELSEN (1999) states that pixels used for website navigation should be kept under $20 \%$. Figure 1 shows the Diercke WebGIS. Approximately 25\% of the website are used by the map, the rest is empty, navigation or the banner. The legend on the left-hand side is also the layer management menu. If a user wants to classify the given data there are small icons within the legend that open a pop-up window for creating individual classes and assigning colors to them. The other WebGIS by a book publisher is from Klett ${ }^{2}$. Two other WebGIS applications are provided by German federal states ${ }^{3}{ }^{4}$ and another available WebGIS is provided by the University of Mainz ${ }^{5}$. All of them are designed in a similar fashion; none provides panning and zooming in an intuitive fashion as popular mapping services do. These WebGIS applications also utilize bulky menus, small icons, and outdated designs.

1 http://diercke.webgis-server.de/

2 http://www.klett-gis.de

3 http://webgis.sn.schule.de/website/Sachsen/viewer.htm

4 http://webgis.bildung-rp.de/

5 http://www.webgis-schule.de/ 
Figure 2 shows another example of the available web services in Germany. This is a screen shot of the aforementioned WebGIS by the German federal state Sachsen. The WebGIS uses ArcIMS to visualize spatial data, features nested layer menus and makes heavy use of pop ups.

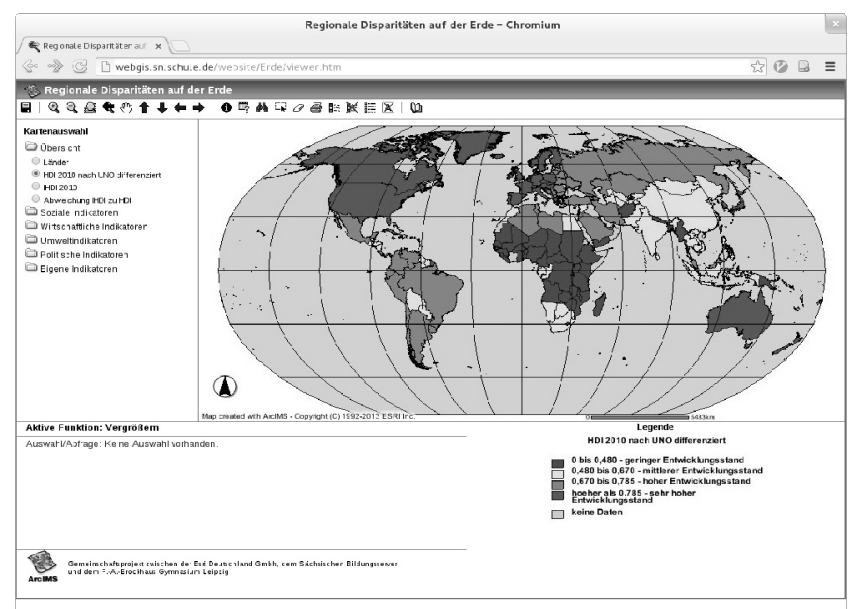

Fig. 2: The WebGIS deployed by the German federal state Sachsen and made available on their education server

The benefits of these applications and other WebGIS are that there is no need for setting up the applications on a computer; they are able to work without prior efforts on any machine featuring an internet connection and a modern web browser (BARTOSCHEK 2009). Teachers also do not have the troubles of acquiring data and other materials. This can also be a disadvantage, as it is not possible to add new data. The available WebGIS applications also make use of basic desktop GIS functionalities such as the layer system, database system and map interactions.

\section{Do We Need Usability Engineering for Educational Software?}

In the German school system the use and application of GIS is being taught in the "Sekundarstufe II". This includes the secondary school, vocational schools evening schools and similar forms of schools. There are several guidelines for the material taught in the classes. The computer science guidelines for German schools do not mention the use of GIS (ARBEITSKREIS BILDUNGSSTANDARDS 2008), but teaching with GIS is particularly described in the guidelines for geography lessons (MINISTERIUM FUER SCHULE UND WEITERBILDUNG DES LANDES NRW 2007). These guidelines specify that students should:

- $\quad$ be able to orientate within Europe and worldwide

- know maps and orientate themselves using such

- know spatial consequences resulting from political decisions

- know how to gather data from sources such as GIS (WebGIS or geodata viewer) 
While the existing WebGIS solutions available to fulfill those goals are basically sufficient and offer some GIS functionality they are not build with the user in mind. It is not possible for pupils to work with these websites without acquiring additional knowledge. NIELSEN (1993) defines usability as consisting of learnability, efficiency, memorability, errors, and satisfaction. This means the software needs to be easy to learn, efficient to use, easy to remember, should not allow users to make errors and be satisfactory to use. HAKLAY \& ZAFIRI (2008) state that there is "lack of research into the way GIS is used at the workplace, in schools, and at home". Designs such as the Diercke WebGIS are acceptable, but there is room for improvement. TRAYNOR \& WILLIAMS (1995) suggest using participatory design as an approach to building new software, TRAYNOR \& WILLIAMS (1997) also state that a program, which is usable by non-specialists, should be free of technical terminology, independent on the software architecture, and expressed in terms of the users tasks. Although written over a decade ago, these statements remain valid and should flow into the design process of any GIS.

It is an important aspect to know your user (HAKLAY 2010). For this paper the targeted user group mainly consists of teenagers of the age from 12 to 16 . This age group has to be distinguished from children below 12. Children and teenagers have very different habits of using technology. They have a different conception of how things work (NIELSEN 2010). Although it is said, that modern teenagers are well connected with the internet, using social networks, owning smart phones or using the web for personal or school tasks, it is a common misconception, that teenagers are efficient and skilled when it comes to technology. Studies show that teenagers have very individual issues in web usability. A study conducted by NIELSEN (2005) shows that the reasons for poor performance in usability are: "insufficient reading skills, less sophisticated research strategies, and a dramatically lower patience level". The study also confirmed that teenagers like "cool looking graphics", modest and clean designs and most important of all no boring sites. There are a few aspects that apply to children as well as to teenagers. For both age groups the first impression of the interface plays a big role, both prefer bigger font sizes and less text to read as their attention span is shorter than the attention span of adults. NIELSEN (2005) also states that interactive features work very well with teenagers and can be used to keep their attention. These differences show that there is a need to put more effort in usability engineering and research towards the use of software by children and teenagers. Especially in times where information technologies and teaching are inevitably coming together more and more as ORTMANN (2012) predicts and classrooms are becoming digital.

\section{A Prototype WebGIS Solution}

In this paper a WebGIS prototype is used for a usability study. The design approach is adapted with the aspects of usability engineering as mentioned in the above section in mind. The web site ${ }^{6}$ is designed to be intuitive, interactive and self-explanatory. Instead of having to acquire a deeper understanding of the geographical knowledge a user can use the application and figure the features out by himself. Figure 3 shows how the prototype looks like. The map, which is the main element of interest, is expanded over the whole browser

6 http://lwl.webgis-westfalen.de 
window, thus using the maximum number of pixels made available by the browser as demanded by NIELSEN (1999). All control elements are within the map. The zoom slider and the scale are on the left side and the icons used to bring up the menus are on the right side. The menus can be opened by clicking on the icons; this triggers a slide animation to draw the user's attention to it. This way all distracting navigation elements can be hidden or visible whether the user chooses to or not. While animations can be used to draw a user's attention to something that has changed, they should not be used to extensively (NIELSEN 1999). There are four icons in total, one for the layer menu, one for the classes menu, one for the legend and one for adding a second map view.

The existing GIS solutions for use in an educational context, which are described above, all utilize the classical layer model to visualize data. This makes it very difficult to directly compare two or more data sets. CINNAMON et al. (2009) describe the advantages of the ability to compare two maps directly: "The ability to compare any of the maps on a single screen almost instantaneously via the use of the split-screen was a benefit for most respondents". They also state, that split screen visualization is an effective way to compare variables in an interactive manner. The prototype makes use of this feature in an intuitive way. Once the icon for split screen mode is clicked, a second map view is opened. If the user pans or zooms within one of the two maps the other one is rearranged accordingly. Both map views act as a single sub-map of the whole application, thus it is possible to configure each view independently from the other one. This feature can be of use when comparing two or more variables, for example to show pupils the spatial correlations of one variable to another. The layer menu provides 5 different thematic layers and several background maps. Behind each thematic layer is a small "i"-icon that gives information about the data in a mouse-over-event. The help texts are kept short and informative. The classes menu is divided into two folding sub-menus. Here users can style the map using automated class breaks or individual breaks. In the automatic break menu the user has to specify what colour ramp to use and how many classes to create. In the individual breaks menu users are able to specify as many classes as desired. The application is designed to ensure fluent animations and fast response times for all interactive features. The loading of new thematic layers takes a moment depending on the network speed, server load and the client's internet connection, but by generalizing geometries and the use of caching mechanisms the loaded data can be diminished to a minimum.

The Prototype has been developed in cooperation with the geographical commission for Westphalia of the LWL (LANDSCHAFTSVERBAND WESTFALEN-LIPPE 2011). The LWL is a municipal association in Germany that runs hospitals, schools or museums and participates in other social areas within the society. The available data used by this commission has been distributed and used in schools before, but has been printed on posters or smaller worksheets; this product was called the "Geographisch-landeskundlicher Atlas von Westfalen" (LANDSCHAFTSVERBAND WESTFALEN-LIPPE 2009) (Atlas of geographical regional and cultural studies in Westphalia). The data records for birth rate, mortality rate, religious confessions; care levels (such as geriatric care) and emigration rates of this atlas have been incorporated into the prototype. The presented WebGIS is an interactive digital product derived from the aforementioned paper atlas. 


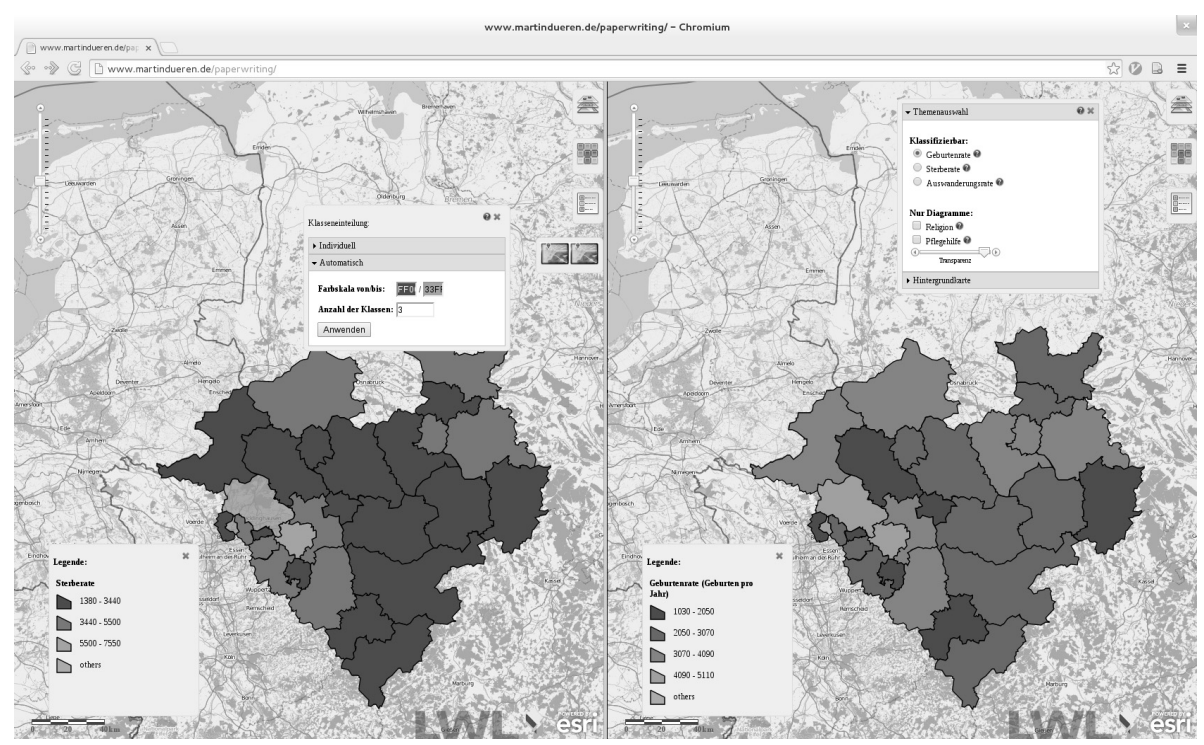

Fig. 3: The prototype GIS: Comparing two maps. All available menus are shown; they can be slid away by pressing the icons on the right-hand side

\section{Testing the Prototype}

We conducted a usability test with pupils to assess the usability of the prototype. This test served solely the purpose of usability testing rather than testing how effective learning with the given set of features proves to be. The aim at this point is to establish usable a WebGIS that reduces the usability threshold for teachers and pupils. Some existing applications copy too much from professional GIS solutions, thus raising the usability barrier considerably for teachers who do not have additional time in their everyday work-life to get involved with the demands of such software (HoEHNLE 2011). Although teaching of GIS is mandatory, the usage of GIS in schools is in fact a rarity (HOEHNLE 2010). The aim is that WebGIS are used more frequently and that improved usability lowers the barriers, thus the usability test concentrates strictly on usability issues. Using the test procedure as described in the following paragraphs we try to prove that it is in fact possible to build a tool usable by pupils and teachers without being familiar with the application.

This test was construed to be a formative evaluation of the prototype, to help improve the given software interfaces (NIELSEN 1993). Test candidates were teenagers between 16 and 17 years old from a German secondary school. In 100 minutes of time we were able to test the prototype with 9 testers, 4 of which were female and the remaining 5 were male. The given number of test users is sufficient as described by NIELSEN (1993), who states that for revealing usability problems a low number of testers suffices, because the count of findings gained through larger numbers of testers levels out very quickly.

The test was set up in a common classroom at their school with a desktop computer as it can be found in almost every classroom. A camera was placed to record all tests. The 
testers were asked to think aloud while working on the given tasks. Immediately after completing the test tasks, the testers were given a questionnaire, in which they were asked to give some information about themselves such as prior knowledge about GIS or experience with computers. Most questions used a semantic differential scale to gain insight into the tester's attitude towards the concepts to be evaluated (NIELSEN 1993).

Of the 9 tested candidates 5 were male and 4 were female. One half of the test candidates estimated that their computer experience is slightly above average, the other half specifies their computer knowledge to be slightly below average; thus no one chose one of the extremes. When asked what they use a computer for in their everyday life all pupils answered "for social media and school". Two male candidates stated that they use a computer also for games and one female candidate used a computer for work outside school. All candidates use web applications for mapping purposes such as Google Maps or Bing Maps from time to time, but not on a regular basis. And although it is a requirement in the German school system to teach GIS using WebGIS or geodata-viewers as specified in MINISTERIUM FUER SCHULE UND WEITERBILDUNG DES LANDES NRW (2007) only two of the testers stated in the questionnaire, that they have used a WebGIS in school before.

\section{Implications from the Test}

In one session 9 software tests have been conducted, during which problems and major issues with the tested prototype became apparent. Figure 4 shows details captured in the usability test. The data shows, that there is no significant difference between male and female testers in regards of performance. The diagram also depicts, that users who spent more time and clicks during the first task, needed significantly less time in the following tasks simply because they discovered more features of the application in the beginning.
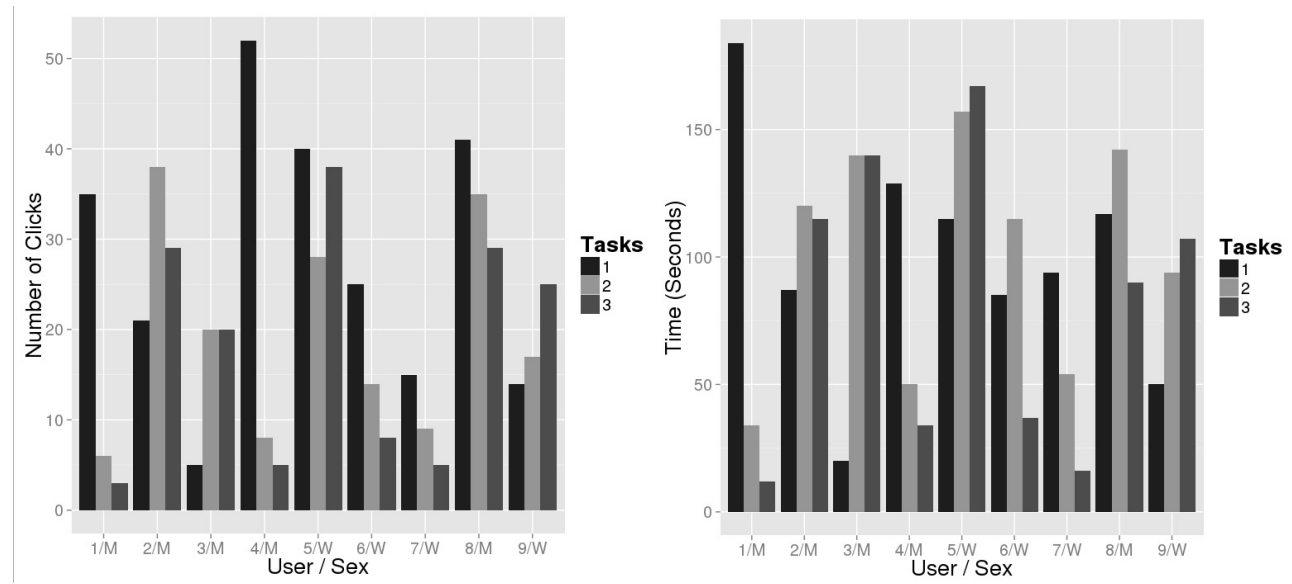

Fig. 4: Left: Bar plot showing a comparison of each testers performance in regards of number of clicks needed to complete each task. Right: The same box plot but showing the time each user needed to complete the tasks. 
The tests showed that pupils tend to miss subtle interface elements. When asked to change the background map in the application some candidates found the appropriate sub menu very fast without detours to other parts of the interface. Most other testers looked for several minutes and clicked on everything they could see. The required menu to change the background map is in a folding menu as shown in Figure 2. Many candidates instinctively clicked on the appropriate icon as a first action, but then tended to overlook that it said Background Map at the bottom. When asked after the test most candidates wished for a more obvious placement for this function or suggested to not have folding menus, which are closed initially.

One other huge issue was the colour picker needed to give a classification of the shown data some colour. The picker uses a JavaScript library that provides a text field containing the visualized colour and the HTML colour code such as "\#FFFFFF"; clicking into the field opens the colour picker. The initial state of this text field is being white and the field is labeled "Colour range from/to:". When asked to give a coloured classification to the shown thematic layer, almost all testers found the appropriate menu very quickly, but upon inspecting the menu did not find anything with colours and dismissed the menu to keep looking somewhere else. The lesson learned here is to make some functions more obvious and to hide anything which could look strange to the end-user such as the HTML colour code. One function proved to be very useful: The help icons. When a user goes over one of these icons a helpful tool tip is displayed without delay. The help in these tool tips is kept very short so they can be read at a glance. Some testers found the helpful tips by accident and remembered to look at them again when they were looking for a specific function. Some functionality still remained unclear for a few test users. For example when users enabled the thematic layer Religion, this does only add an invisible layer over the previously selected thematic layer. Information about religious confessions can be shown by clicking on a place within the map, which would display a diagram. The tool tip belonging to the thematic layer Religion states to click into the map to see the diagrams. This function is something which is typically not obvious to the user; thus a user needs a tip. Not all users used the given help icons and did not find the diagrams or could make any sense of this thematic layer.

Providing additional help is required, this help could come in the form of Android style Toast $^{7}$ messages whenever a function is enabled that needs further explanation. The tests have also shown which parts of the interface work good. As mentioned above the help icons were a success, as well as the split mode to compare maps. The split mode button was easily found by almost all testers when asked to compare two maps and some of them stated afterwards that they liked the intuitive nature of this function. Most test users also stated in the questionnaire that they liked the overall design and button placement. While most testers answered that they liked the button sizes, the opinions about adequate fitting symbols differed. Some found the icon symbols confusing, and others liked them. Combining purely symbolic icons with text is a suggested approach by (NIELSEN 1993), this approach is also backed by studies that show the improved performance and memorability of such icons; this shows that there is room for improvement.

\footnotetext{
7 http://developer.android.com/guide/topics/ui/notifiers/toasts.html
} 


\section{Conclusions and Outlook}

The presented WebGIS prototype tries to improve on the existing solutions available for teaching in schools by using modern technologies. To answer the question which requirements are needed for a WebGIS to work in an educational environment, the interface was changed and adapted according to key aspects regarding web usability as described in the literature and discussed in this paper. By using various usability-testing methods the interface has been tested in a real world environment to evaluate the changes made. We confirmed the hypothesis that it is possible to implement a usable WebGIS using currently available technologies in the use case with pupils. The main implications for the prototype gained from the usability tests are to focus on flat menu structures and avoid folding menus and also make it obvious which elements are clickable. Other mistakes in our design approach were that we did not hide some obfuscating elements such as HTML color codes. The hover-over help icons stuck out very positively and users liked them, but in more complicated tasks additional help is needed. This shows, that in addition to considering basic design concepts recommended for the target audience, it is necessary to heavily rely on usability testing and engineering when it comes to implementing software for young users. Future research has to go into testing an interface which is more complex and packed with more features as the presented web application. The prototype merely provided basic functionality to test basic design concepts Future versions may feature more complex menus and data structures. Also especially in an educational context it is important to include the teachers in the research process with additional usability tests, questionnaires or by letting them take part in the design process as it is them who have to use the software to teach.

\section{References}

ARBEITSKREIS BildungsstandARDS (2008), Grundsätze und Standards für die Informatik in der Schule. http://www.sn.schule.de/ istandard/docs/bildungsstandards_2008.pdf (November 13, 2012).

BArtoscheK, T. (2009), WebGIS für die Schule - Ein Überblick. Praxis Geographie, $2(12-13)$.

Cinnamon, J., Rinner, C., Cusimano, M., Marshall, S., Bekele, T., Hernandez, T., GlazIER, R. \& ChIPMAN, M. (2009), Evaluating web-based static, animated and interactive maps for injury prevention. Geospatial Health, 4 (1), 3-16.

CommitTee on Support fOR Thinking SPATIALly (2006), The Incorporation of Geographic Information Science Across the K-12 Curriculum, N. R. C. Learning to think spatially. Washington, DC, National Academies Press.

GERMAN ASSOCIATION FOR GEOGRAPHY (2007), Educational Standards in Geography for the Intermediate School Certificate.

http://www.geographie.de/docs/geography_education.pdf (November 13, 2012).

GoodCHILD, M. (1992), Geographical information science. International Journal of Geographical Information Systems, 6 (1), 31-45.

GoodchILD, M. (2006), The Fourth R? Rethinking GIS Education. ESRI ArcNews, 28 (3), p. 1, 5. http://www.esri.com/news/arcnews/fall06articles/the-fourth-r.html.

(December 1, 2012). 
HAKLAY. M. (2010), Interacting with Geospatial Technologies. John Wiley \& Sons.

HAKLAY, M. \& ZAFIRI, A. (2008), Usability Engineering for GIS: Learning from a Screenshot. The Cartographic Journal, 45 (2), 87-97.

Höhnle, S., Schubert, J. C. \& Uphues, R. (2010), The frequency of GI(S) use in the geography classroom. Results of an empirical study in German secondary schools. In: JeKel, T., Koller, A., Donert, K. \& Vogler, R. (Eds.), Learning with Geoinformation V. Berlin/Offenbach, Wichmann, 148-158.

HöHnle, S., Schubert, J. C. \& Uphues, R. (2011), Barriers to GI(S) Use in Schools A comparison of International Empirical Results. In: JEKEL, T., KOLLER, A., DONERT, K. \& Vogler, R. (Eds.), Learning with GI. Implementing Digital Earth in Education. Berlin/Offenbach, Wichmann, 124-133.

LANDSCHAFTSVERBAND WESTFALEN-LIPPE, GEOGRAPHISCH-LANDESKUNDLICHER ATLAS VON WESTFALEN (2009).

http://www.lwl.org/geko-download/Atl_Ausschnitte/Atlasprospekt_2009.pdf. (November 13, 2012).

LANDSCHAFTSVERBAND WESTFALEN-LIPPE, LWL GEOGRAPHISCHE KOMMISSION (2011), http://www.lwl.org/LWL/Kultur/Westfalen_Regional/Gebiet_Identitaet/GeKo_LWL/Ge Ko (February 1, 2013).

Milson, A., Demirici, A. Kerski, J. (2011), International Perspectives on Teaching and Learning with GIS in Secondary Schools. Berlin/Heidelberg/New York, Springer.

MINISTERIUM FUER SCHULE UND WEITERBILDUNG DES LANDES NRW (2007), Kernlehrplan für das Gymnasium Sekundarstufe I (G8) in Nordrhein-Westfalen - Erdkunde.

NiELSEN, J. (1993), Usability Engineering. San Francisco, Morgan Kaufmann.

NiELSEN, J. (1999), Designing Web Usability: The Practice of Simplicity. David Dwyer.

NIELSEN, J. (2005), Usability of Websites for Teenagers.

http://www.useit.com/alertbox/teenagers.html (November 13, 2012).

Nielsen, J. (2010), Children's Websites: Usability Issues in Designing for Kids. http://www.useit.com/alertbox/children.html (November 13, 2013).

ORTMANN, Y. (2012), Das Netz als Klassenzimmer. t3n, 29, 70-73.

TOMLinson, R. (1967), An Introduction to the Geographic Information System of the Canada Land Inventory. Department of Forestry and Rural Development, Ottawa, Canada.

TraynOR, C. \& Williams, M. (1995), Why are Geographic Information Systems Hard to Use? In: CHI95 Mosaic of Creativity, 288-289, Denver, USA.

TRAYNOR, C. \& WILliamS, M. (1997), A study of end-user programming for geographic information systems. In Proceeding ESP '97 Papers presented at the seventh workshop on Empirical studies of programmers, 140-156, New York, USA. 